\title{
Huge Biobank project launches despite critics
}

British family doctors have started recruiting subjects for an ambitious effort to probe the interplay of genetic and environmental factors that cause disease.

Researchers hope that half a million people will donate blood and urine samples, and give access to their medical records, as part of UK Biobank. This £61-million (US\$105-million) project launched on $13 \mathrm{March}$, funded by the Medical Research Council and the Welloome Trust. Critics question whether it will give value for money. But the project's organizers say it has enormous research potential.

Participants will be weighed and measured, and answer questions on topics such as alcohol intake and family medical history. Details will be held in a database and linked to records collected by the National Health Service (NHS).

Thousands of cases of conditions such as heart disease and cancer are likely to develop,

and researchers will be able to search the database for underlying genes and lifestyle choices. Critics, including members of the House of Commons Select Committee on Science and Technology, say health records alone can be a poor guide to the conditions a person suffers

"Complaints stem in partfrom a misunderstanding of the scheme." from. Medical journals have asked whether enough cases of disease will develop for results to be statistically meaningful. In contrast to some other genetic-database projects, however, critics are not concerned about data-privacy and ethical issues.

UK Biobank's chief executive, Rory Collins, an epidemiologist at the University of Oxford, says complaints stem in part from a misunderstanding of the scheme. It might make sense to study the families of ill people if disease genes were the main target, he says, but they are not.

${ }^{\alpha}$ The primary use will be to compare people who develop disease with those that don't," he says. Researchers will then be able to examine the lifestyle and genetic factors that differentiate the two groups.

Collins estimates that scientists will want to start mining the database in about ten years, when several thousand cases of diseases will have emerged. He adds that changes in the NHS computer system should have made it easier for scientists to use for research by then.

Access will be controlled by UK Biobank, which will vet applications and coordinate groups to minimize the cost of accessing samples. These will be frozen and split between two locations, to provide a back-up.

The UK project will be tracked in countries with similar schemes. Canada, Iceland and Japan have set up smaller biobanks. Work began in 2001 on a project in Estonia, where the government wants to collect genealogical, health and DNA data on a million citizens - it aims to have data on some 100,000 by 2009 . Jim Giles 